Journal of Animal and Feed Sciences, 19, 2010, 452-459

\title{
Genetic relationships among time of egg formation, clutch traits and traditional selection traits in laying hens
}

\author{
A. Wolc ${ }^{1,2}$, M. Bednarczyk ${ }^{3}$, M. Lisowski ${ }^{4}$ and T. Szwaczkowski ${ }^{1,5}$ \\ 'Poznan University of Life Sciences, Department of Genetics and Animal Breeding \\ Wolyńska 33, 60-637 Poznań, Poland \\ ${ }^{2} I o w a$ State University, Department of Animal Science \\ Ames, Iowa 50011-3150, USA \\ ${ }^{3}$ University of Technology and Life Sciences, Department of Animal Biotechnology \\ Ks. Kordeckiego 20, 85-225 Bydgoszcz, Poland \\ ${ }^{4}$ National Research Institute of Animal Production, \\ Department of Animal Reproduction Biotechnology \\ 32-083 Balice, Poland
}

(Received 11 March 2010; revised version 21 June 2010; accepted 16 August 2010)

\begin{abstract}
In a population of Rhode Island White hens heritability of egg formation, clutch characters and traditional selection traits as well as the genetic and phenotypic correlations between them were estimated via multitrait animal model. Over 1300 birds and about 4000 birds were recorded in two consecutive generations for oviposition time and traditional traits, respectively. The heritability estimates obtained for age at first egg $\left(\mathrm{h}^{2}=0.42\right)$, egg weight $\left(\mathrm{h}^{2}=0.50\right)$ and body weight $\left(\mathrm{h}^{2}=0.42\right)$ werc considerably higher than those for initial egg production $\left(h^{2}=0.22\right)$, clutch traits $\left(h^{2}\right.$ between 0.11 and 0.23 ) and oviposition time $\left(\mathrm{h}^{2}\right.$ between 0.13 and 0.19$)$. Both genetic and phenotypic correlations between clutch traits and traditional selection traits were low, except for initial egg production and maximal clutch length $\left(r_{g}=0.40\right.$ and $r_{p}=0.38$ ). As expected, negative correlations were registered for number of clutches and average clutch length. It indicates an opportunity of selection aimed at improvement of egg production persistence by an increase in the average clutch size. Oviposition time was favourably correlated with traditional selection criteria.
\end{abstract}

KEY WORDS: laying hens, oviposition time, clutch traits, heritability, correlations

\footnotetext{
${ }^{5}$ Corresponding author: e-mail: tomasz@jay.up.poznan.pl
} 


\section{INTRODUCTION}

It is well known that long term selection in laying hens led to substantial decrease of genetic variability in traditional selection traits, for instance initial egg production, egg weight, body weight and age at first egg (Szwaczkowski, 2003). Therefore, other groups of traits describing egg production such as clutch traits were considered as a potential selection criterion (Sheldon and Yoo, 1993). Formation of clutches results from longer than $24 \mathrm{~h}$ time needed for egg formation (Bednarczyk et al., 2000; Chen and Tixier-Boichard, 2003a). Therefore analysis of time interval between consecutively laid eggs seems closer to the physiology of the egg production process. Bird ovulatory cycle is thought to be controlled by a circadian rhythm, entrained by the daily light-dark cycle, that governs the timing of the preovulatory surge of luteinizing hormone and by the growth and maturation of the follicles. More details on physiological background of egg formation are given by Lillpers (1993).

The laying rhythm has been studied for several species of domestic fowls, for instance laying hens (Lillpers and Wilhelmson, 1993; Luc et al., 1996, Bednarczyk et al., 2000), ducks (Simmons and Hetzel, 1983), geese (Rosinski et al., 2006) and turkeys (Pyrzak and Siopes, 1989). In general, the results seem to be promising. Miandmients et al. (1993) found positive relationship between egg production and clutch length. However, majority of above mentioned studies were based on evaluation of phenotypic relationship between 'new' and 'classical' egg production traits.

It should be stressed that the data from the population used in this study were analysed by Bednarczyk et al. (2000) using the sire-dam model without integrating connections and additional relationships between individuals. Thus, it could have led to overestimation of residual variances and, in consequence, bias in the estimates of genetic parameters of the studied traits. Nowadays, the advantages of animal model with full relationship matrix over sire-dam model to analyse genetic and phenotypic parameters of multigenerational populations seem to be evident.

The objectives of this study were to estimate the heritability of egg formation, clutch characters and traditional selection traits as well as the genetic and phenotypic correlations between them via multitrait animal model.

\section{MATERIAL AND METHODS}

Two consecutive generations of the A22 line(Rhode Island White) were recorded. The genetic improvement programme applied is based on classical selection index including five traits: initial egg production, rate of initial egg production, body weight, average egg weight and age at first egg. More details on the selection 
index applied were described by Wezyk and Szwaczkowski (1997). The study was undertaken at Poultry Research Branch of National Research Institute of Animal Production at Zakrzewo near Poznan (Poland). From eighteenth week of life birds were kept in individual cages with $750 \mathrm{~cm}^{2}$ per hen. After stimulation period light:dark time ratio was 14:10 h. Compound feed in mash form was provided $a d$ libitum. Temperature and humidity were automatically controlled. A total of 720 cages were connected to a computer device that automatically recorded time and cage in which an egg was laid. Each bird from such cage was characterized for within clutch time of egg formation from first oviposition until the $64^{\text {th }}$ week of age using an electronic data collection system described by Bednarczyk et al. (1997). Bar code and hen number expressed in digits placed in front of cage identified each hen. At oviposition the data read from the mark were recorded by the LAG950 Laser Reader, coded in the memory of BCP-601 terminal and then transferred to the computer for further analysis. The records were used to define the following traits: mean oviposition time (MT), within bird variance of oviposition time (VT), minimum oviposition time (MINT), maximum oviposition time (MAXT) for hens in the experimental setting. Other production traits were also measured for all hens from the given generation. Based on individual daily egg records number of clutches (CN), average (CS) and maximal (MCS) clutch length and initial egg production (IEP-38 $8^{\text {th }}$ week of life) were determined. Additionally traits included in the selection index were measured: body weight (BW) at thirty weeks, age at first egg (AFE) and egg weight (EW).

Statistical description of these data is given in Table 1 .

Table I. Description of the data set

\begin{tabular}{lcrr}
\hline Trait $^{\prime}$ & $\begin{array}{c}\text { Number of recorded } \\
\text { individuals }\end{array}$ & Mean & SD \\
\hline AFE, days & 4131 & 147.44 & 10.59 \\
IEP, psc & 4081 & 112.33 & 14.23 \\
EW, g & 3976 & 58.57 & 4.15 \\
BW, g & 4129 & 1940.0 & 187.7 \\
CN & 4118 & 32.47 & 12.36 \\
CS, psc & 4122 & 9.10 & 5.07 \\
MCS, psc & 4116 & 49.19 & 24.68 \\
MT, hours & 1369 & 24.09 & 0.25 \\
VT, squared hours & 1350 & 1.59 & 1.20 \\
MINT, hours & 1370 & 21.03 & 1.36 \\
MAXT, hours & 1373 & 27.28 & 1.36 \\
\hline
\end{tabular}

${ }^{1}$ AFE - age at first egg, IEP - initial egg production, EW - egg weight, BW - body weight, $\mathrm{CN}$ - number of clutches, CS - average clutch lenght, MCS - maximal clutch length, MT - mean oviposition time, VT - variance of oviposition time, MINT - minimal oviposition time, MAXT - maximal oviposition time 
The following multitrait animal model was employed:

$$
\mathbf{y}=\mathbf{X b}+\mathbf{Z a}+\mathbf{e}
$$

where: $\mathbf{y}$ - the $(\mathrm{N} \times 1)$ vector of observations on $t$ traits with following form: $\mathbf{y}=\left(\mathbf{y}_{1}, \mathbf{y}_{2}, \ldots, \mathbf{y}_{\mathbf{i}}\right) ; \mathbf{b}$ - the (pt $\left.\mathbf{x} 1\right)$ vector of fixed effects ( two years and eight hatch periods) with following form: $\mathbf{b}=\left(\mathbf{b}_{1}, \mathbf{b}_{2}^{\prime}, \ldots, \mathbf{b}_{\mathbf{t}}\right) ; \mathbf{a}$ - the (qt $\times 1$ ) vector of random additive genetic effects with following form: $\mathbf{a}=\left(\mathbf{a}_{1}^{\prime}, \mathbf{a}_{2}^{\prime}, \ldots, \mathbf{a}_{1}^{\prime}\right) ; \mathbf{e}$ - the $(\mathrm{Nx} 1)$ vector of random errors with following form: $\mathbf{e}=\left(\mathbf{e}_{1}^{\prime}, \mathbf{e}_{2}^{\prime}, \ldots, \mathbf{e}_{\mathbf{t}}\right) ; \mathbf{X}$ and $\mathbf{Z}$ are $\mathrm{N} \mathrm{xpt}$ and $\mathrm{N} x$ qt these incidence matrices for fixed and random effects, respectively. Whereas $\mathbf{X}=\left(\mathbf{I}_{\mathbf{t}} \otimes \mathbf{X}_{\mathbf{i}}\right)$ and $\mathbf{Z}=\left(\mathbf{I}_{\mathbf{t}} \otimes \mathbf{Z}_{\mathbf{i}}\right)$ with $\mathbf{X}_{\mathbf{i}}$ and $\mathbf{Z}_{\mathbf{i}}$ are the incidence matrices for single trait, $\mathbf{I}_{\mathbf{1}}$ is diagonal matrix and $\otimes$ denotes Kronecker product.

Traits were analysed in groups of seven due to computing demands with the same model used for all traits. REML approach was applied to estimate variance components in the DXMUX programme which belongs to the DFREML package (Meyer, 2001).

The following parameters were estimated: heritability, genetic and phenotypic correlations. Standard deviations of heritability estimates were derived from the average information matrix (Meyer, 2001).

\section{RESULTS AND DISCUSSION}

Estimates of heritability of the studied traits as well as genetic and phenotypic correlations between them are listed in Table 2. Generally, the heritability estimates obtained for classical characters (especially AFE, EW and $\mathrm{BW}$ ) were considerably higher than those for clutch traits. It should be recalled that these traits and IEP have been included in selection index applied to the studied population. A number of reports on heritabilites of the so-called classical traits are available in the literature (see Szwaczkowski, 2003). The effectiveness of the current genetic improvement programme in the population can be implied from the estimates of genetic parameters of classical traits. Body weight, egg weight and age at first egg were moderately heritable, whereas for traits directly related to egg production lower estimates of heritability were obtained. A wide range of heritability estimates of traditional selection traits are available in the literature. For instance, heritability of body weight varies for both layer and broiler chicken (Bednarczyk et al., 2000; Szydlowski and Szwaczkowski, 2001; Zieba et al., 2003). Egg weight was found to be moderately heritable in the study herein. Similar estimates were obtained by Nurgiartiningsih et al. (2004) for 
White Leghorns as well as by Zieba et al. (2003) for Rhode Island strains. Body weight was positively correlated with egg weight, however the correlation was not very high ( 0.25 at the phenotypic and 0.21 at the genetic level). It corresponds to the results published so far (Szwaczkowski, 2003).

Table 2. Estimates of heritabilities and their standard deviations in the diagonal, genetic correlations (above diagonal) and phenotypic correlations (below diagonal) betwecn traits ${ }^{1}$ studied

\begin{tabular}{|c|c|c|c|c|c|c|c|c|c|c|c|}
\hline Traits & AFE & IEP & EW & BW & $\mathrm{CN}$ & $\mathrm{CS}$ & MCS & MT & VT & MINT & MAXT \\
\hline AFE & $\begin{array}{c}0.42 \\
( \pm 0.04)\end{array}$ & -0.878 & 0.013 & 0.031 & -0.160 & 0.110 & -0.1193 & 0.1562 & -0.4249 & 0.2831 & -0.0957 \\
\hline IEP & -0.595 & $\begin{array}{c}0.22 \\
( \pm 0.03)\end{array}$ & -0.028 & 0.038 & -0.079 & 0.129 & 0.4001 & -0.3672 & 0.3391 & -0.3007 & 0.1802 \\
\hline EW & -0.018 & 0.044 & $\begin{array}{c}0.50 \\
( \pm 0.04)\end{array}$ & 0.215 & -0.027 & 0.040 & -0.1301 & -0.1635 & $5-0.4141$ & 0.1581 & -0.0889 \\
\hline BW & -0.195 & 0.147 & 0.253 & $\begin{array}{c}0.42 \\
( \pm 0.04)\end{array}$ & -0.126 & 0.124 & -0.0976 & 50.1048 & 0.1135 & -0.0107 & 0.0224 \\
\hline $\mathrm{CN}$ & -0.036 & -0.294 & -0.036 & -0.159 & $\begin{array}{c}0.23 \\
( \pm 0.04)\end{array}$ & -0.989 & -0.813 & 0.577 & 0.195 & 0.257 & 0.163 \\
\hline CS & -0.030 & 0.329 & 0.042 & 0.152 & -0.791 & $\begin{array}{c}0.23 \\
( \pm 0.03)\end{array}$ & 0.885 & -0.558 & -0.175 & -0.283 & -0.112 \\
\hline MCS & 0.022 & 0.382 & -0.004 & 0.011 & -0.518 & 0.572 & $\begin{array}{c}0.11 \\
( \pm 0.02)\end{array}$ & -0.323 & -0.210 & -0.240 & -0.030 \\
\hline MT & 0.162 & -0.178 & -0.011 & -0.130 & 0.265 & -0.220 & -0.139 & $\begin{array}{c}0.13 \\
( \pm 0.05)\end{array}$ & -0.478 & 0.580 & -0.178 \\
\hline VT & 0.048 & -0.025 & -0.014 & -0.023 & 0.077 & -0.092 & -0.037 & 0.047 & $\begin{array}{c}0.18 \\
( \pm 0.02)\end{array}$ & -0.827 & 0.615 \\
\hline MINT & -0.121 & -0.016 & -0.006 & 0.047 & 0.112 & -0.104 & -0.190 & 0.256 & -0.626 & 0.19 & -0.534 \\
\hline MAXT & 0.158 & -0.035 & -0.012 & -0.103 & -0.001 & 0.012 & 0.145 & 0.238 & 0.646 & $\begin{array}{r}( \pm 0.06) \\
-0.544\end{array}$ & $\begin{array}{c}0.19 \\
( \pm 0.07)\end{array}$ \\
\hline
\end{tabular}

${ }^{1} \mathrm{AFE}$ - age at first age, IEP - initial egg production, EW - egg weight, $\mathrm{BW}$ - body weight, $\mathrm{CN}$ - number of clutches, CS - average clutch length, MCS - maximal clutch length, MT - mean oviposition time, VT - variance of oviposition time, MINT - minimal oviposition time, MAXT - maximal oviposition time

As it was already mentioned, initial egg production was characterized by lower heritability. It is caused by long term selection on this trait. It is well known that estimates from commercial populations are usually lower than from experimental or local breeds. Because of decreased heritability and genetic progress for initial or total egg production, new measurements were tested for their usefulness in the breeding programmes. The first group of these traits were clutch traits. In the studied population $23 \%$ of the variation of number of clutches and average clutch length was attributed to genetic factors. However, these estimates are negligibly higher than obtained by Bednarczyk et al. (2000) via sire+dam model for this population. Heritability estimate for maximal clutch length was lower (0.11) than these found 
for $\mathrm{CN}$ and $\mathrm{CS}$. As expected, the heritability estimates reported by other authors varied depending on the type of population under study and statistical model. Chen and Tixier-Boichard (2003b) concluded that average clutch size can be effectively improved by selection in dwarf laying hens whereas the selection response was not considerably affected by naked neck gene. The heritability estimates by Chen and Tixier-Boichard (2003b) were relatively higher than ones estimated in the present study, but it should be mentioned that they were obtained for transformed data. It is well know that data transformation often leads to higher heritability estimates since an empirical distribution of given trait better approximates normality. On the other hand, high estimates for untransformed observations of clutch traits in two lines of laying hens were found by Luc et al. (1996). Various estimates of heritability (from sire, dam and sire+dam components) for laying rhythm in geese were estimated by Rosinski et al. (2006). It may indicate a more complex genetic background of these traits. Both genetic and phenotypic correlations between clutch traits and traditional selection traits were low, except for initial egg production and maximal clutch length $\left(r_{\mathrm{g}}=0.40\right.$ and $\left.r_{p}=0.38\right)$. As expected, negative correlations were registered for number of clutches and average clutch length. It indicates an opportunity of selection aimed at improvement of egg production persistence by an increase in the average clutch size. Clutch traits were extensively evaluated over the last decades. The different approaches included sire+dam model (Bednarczyk, 2000), and animal model estimates confirmed by selection experiment (Chen and Boichard, 2003b). Selection experiment proved that it is possible to obtain significant progress in clutch length and that correlated response can be achieved in egg number.

The studies on oviposition times were already carried out in the 1970s (McClung et al., 1976); however, they were newly undertaken in the XXI century (Lewis et al., 2004) due to reduced selection response in the traditional selection criteria applied in layer populations. Average time between eggs in the studied population was 24.09 $\mathrm{h}$; however, the average minimal time was slightly above $21 \mathrm{~h}$, which suggests a high range for further improvement. The heritability of minimal and maximal times between ovipositions was almost 0.2 which is similar to the level estimated for initial egg production in the studied population. Temporal laying organization was also studied in quails (Houdelier et al., 2002). As it was already mentioned the heritability estimate for mean oviposition time was relatively low $(0.13)$, whereas the parameters for traits describing variability of time of egg formation were higher. Low heritability $\left(\mathrm{h}^{2}=0.09\right)$ of time interval was recently reported in Leghorn hens by Icken et al. (2008). However, Lillpers (1991) reported heritability estimates of time of oviposition ranging from 0.38 to 0.78 . The genetic and phenotypic relationships between these traits and classical ones are basically favourable, resulting from the biological background of egg formation. For instance, when an increase in initial egg production is genetically associated with a decrease of average time of oviposition 
$\left(r_{\mathrm{g}}=-0.37\right)$. Also a favourable genetic correlation was estimated between average egg weight and mean time of oviposition.

The results suggest a possibility of effective selection for improvement of egg production traits; but, from economical perspective, other important characters should be included into the analysis. It is well known, that egg quality and reproductive traits are determined by a number of factors. An investigation carried out by Tumova et al. (2007) indicated a significant phenotypic relationship between oviposition time and egg quality. So far, Tumova and Ebeid (2005) reported that eggs laid in the morning had a slightly higher ratio of yolk than eggs laid in the afternoon. Effects of oviposition time on reproductive traits have been examined by Zakaria et al. (2009).

\section{CONCLUSIONS}

Generally, substancial amount of genetic vriation was found for egg formation and traditional selection traits. However, it should be recalled that both genetic and phenotypic influences on the performance traits are always estimated for the given population. Hence, generalization of the results for oviposition time and clutch size should be done carefully, especially considering small population size. On the other hand, the obtained results seem to be promising and stimulating for further studies on including the clutch and oviposition traits in genetic improvement programmes in laying hens.

\section{ACKNOWLEDGEMENTS}

The authors would like to thank Dr. Jesus Arango for helpful comments on the draft version of the manuscript.

\section{REFERENCES}

Bednarczyk M., Kiełczewski K., Szwaczkowski T., 2000. Genetic parameters of the traditional selection traits and some clutch traits In a commercial line of laying hens. Arch. Geflügelk. 64, 129-133

Bednarczyk M., Lisowski M., Kiełczewski K., Skórnicki G., 1997. Construction of optimal selection indexes on basis electronic control of egg production in chicken (in Polish). Report Z-5/96 COBRD, Poznań (Poland)

Chen C.F., Tixier-Boichard M., 2003a. Correlated responses to long-term selection for clutch length in dwarf brown-egg layers carrying or not carrying the naked neck gene. Poultry Sci. 82, 709-720

Chen C.F., Tixier-Boichard M., 2003b. Estimation of genetic variability and selection response for clutch length in dwarf brown-egg layers carrying or not the naked neck gene. Genet. Sel. Evol. $35,533-537$ 
Houdelier C., Guyomarch C., Luniincau S., 2002. Daily temporal organization of laying in Japanese quail: variability and heritability. Chronobiol. Int. 19, 377-392

Icken W., Cavero D., Schmutz M., Thurner S., Wendl G., Preisinger R., 2008. Analysis of the time interval within laying sequences in a Transponder nest. In: Proceedings of XXII World Poultry Congress. Brisbane (Australia)

Lewis P.D., Backhouse D., Gous R.M., 2004. Photoperiod and oviposition time in broiler breeders. Brit. Poultry Sci. $45,561-564$

Lillpers K., 1991. Genetic variation in the time of ovipostion in the laying hens. Brit. Poultry Sci. $32,303-312$

Lillpers K., 1993. Oviposition patterns and egg production in domestic hens. Dissertation. Swedish University of Agricultural Sciences, Department of Animal Brceding and Genetics, Uppsala

Lillpers K., Wilhelmson M.W., 1993. Genetic and phenotypic parameters for oviposition pattern traits in three selection lines of laying hens. Brit. Poultry Sci. 34, 297-308

Luc K.M., Miyoshi S., Suzuki M., Mitsumoto T., 1996. Heritability estimates of some clutch traits in laying hens. Jpn. Poultry Sci. 33, 23-28

McClung M.R., Wang A.B.S., Jones W.T., 1976. Response to selection for time interval between oviposition time in the hen. Poultry Sci. 33, 23-28

Meyer K., 2001. DFREML ver. 3.1. University of New England (Australia)

Miandmients P., Hiammal J., Rummiel K., 1993. Length of eggs' clutches and time intervals in white and brown layers (in Russian). Pticevodstvo 42, 14-15

Nurgiartiningsih V.M.A., Mielenz N., Preisinger R., Schmutz M., Schueler L., 2004. Estimation of genetic parameters based on individual and group mean records in laying hens. Brit. Poultry Sci. $45,604-610$

Pyrzak P., Siopes T.D., 1989. Characteristics of oviposition patterns of turkey hens and the influence of different wavelenght of light. Brit. Poultry Sci. 31, 871-879

Rosinski A., Nowaczewski S., Kontecka H., Bednarczyk M., Elminowska-Wenda G., Bielinska H., Maczynska A., 2006. Analysis of the laying rhythm and reproductive traits of geese. Folia Biol. - Krakow 54, 145-152

Sheldon B.L., Yoo B.H., 1993. Egg genetics - future prospects. In: Proceedings of $10^{\text {th }}$ International Symposium on Current Problems of Avian Genetics. Nitra (Slovakia), pp. 49-54

Simmons G.S., Hetzel D.J.S., 1983. The relationships between oviposition, ovulation and egg formation in Khaki Campbell ducks. Brit. Poultry Sci. 24, 21-29

Szwaczkowski T., 2003. Use of mixed model methodology in poultry brecding: Estimation of genetic parameters. In: W.M. Muir, S.E. Aggrey (Editors). Poultry Genetics, Brceding and Biotechnology. CAB Int. 11, 165-201

Szydlowski M., Szwaczkowski T., 2001. Bayesian segregation analysis of production traits in two strains of laying chicken. Poultry Sci. 80, 125-131

Tumova E., Ebeid T., 2005. Effect of time of oviposition on egg quality characteristics in cages and in a litter housing system. Czech J. Anim. Sci. 50, 129-134

Tumova E., Zita L., Hubeny M., Skrivan M., Ledvinka Z., 2007. The effect of oviposition time and genotype on egg quality characteristics in egg type hens. Czech J. Anim. Sci. 52, 26-30

Wezyk S., Szwaczkowski T., 1997. Application of mixed model methodology in breeding strategies for laying fowl. World Poultry Sci. J. 53, 325-336

Zakaria A.H., Plumstead P.W., Romero-Sanches H., Leksrisompong N., Brake J., 2009. The effects of oviposition time on egg weight loss during storage and incubation, fertility, and hatchability of broiler hatching eggs. Poultry Sci. 88, 2712-2717

Zieba G., Lukaszewicz M., Twardowska M., Witkowski A., 2003. Genetic trends of laying merit in maternal (M55) and paternal (V44) strains of hens. Anim. Sci. Pap. Rep. 21, 241-249 